\title{
Ischemic cerebrovasular accident, uncontrolled seizures and acute myocardial infarction associated with synthetic marijuana abuse
}

\author{
Farah Hussain $^{1}$, Hanan Al-musawi ${ }^{1}$, Eman Al-khateeb ${ }^{2,}$, Alaa Abu sayf ${ }^{1}$ \\ ${ }^{1}$ Sinai-Grace Hospital / Detroit Medical Center, Detroit, MI, United States \\ ${ }^{2}$ Department of Physiology and Biochemistry, Faculty of Medicine, University of Jordan, Amman, Jordan
}

\section{Email addresses:}

Farah.hussain83@yahoo.com (F. Hussain), hanan_baha87@yahoo.com (H. Al-musawi), profemanalkhateeb@yahoo.com (E. Al-khateeb), alaa_a82@hotmail.com (A. A. sayf)

\section{To cite this article:}

Farah Hussain, Hanan Al-musawi, Eman Al-khateeb, Alaa Abu sayf. Ischemic Cerebrovasular Accident, Uncontrolled Seizures and Acute Myocardial Infarction Associated with Synthetic Marijuana Abuse. American Journal of Internal Medicine. Vol. 2, No. 6, 2014, pp. 138-143. doi: 10.11648/j.ajim.20140206.17

\begin{abstract}
Introduction: Designer Cannabinoids is a newly emerging drug of abuse that gained popularity among adolescent and young adults in the past few years. These drugs are marketed as incense or potpourri under different brand names such as spice. The potency of these drugs is variable and the range of adverse effects range from simple to severe and life threatening adverse effects such as myocardial infarction (MI), Ischemic cerebrovasular accident (ICVA) and seizures. Case report: we describe a 23 male patient who was admitted to the hospital several times suffering from severe side effects following spice abuse. In his first admission, he provided spice sample that we later confirmed to have at least two different synthetic cannabinoids. In his last admission for uncontrolled seizures he start feeling chest pain which was later diagnosed as acute MI. This appears to be the first case report where a spice abuser develops ICVA, uncontrolled seizures and MI at the same time with negative work up towards the etiology other than spice abuse. Discussion: the mechanism behind the possible proconvulsant effect of synthetic marijuana is not known, but it may be due to either their effects at the cannabinoids receptor or due to the absence of the anticonvulsant phytocannabinoids in spice products. Synthetic cannabinoids cause tachycardia and vasospasm due to their high affinity to cannabinoid receptors and this may lead to acute MI however the deep inhalation adopted by spice smokers increase carboxyhemoglobin concentrations and may also contribute to this atheromatous disease. Conclusion: given the patient negative history for thromboembolization, vasculitis, and hypercoagulable state, and the multiple admissions of this patient after smoking spice suggest an association. We hypothesize that synthetic marijuana or the herbs mixed with it might cause the ICVA, MI and seizures in his last admission. Based on extensive review of the literature this appears to be the first case report where a single spice abuser developed ICVA, uncontrolled seizures and MI with negative workup towards the etiology other than spice abuse. Screening for synthetic marijuana should be warranted in all teenagers with new onset seizure disorder. Furthermore, the possibility of MI and ICVA should be part of teenager's counseling sessions as by now it is increasingly reported in literature.
\end{abstract}

Keywords: Synthetic Marijuana, Synthetic Cannabinoid, Ischemic Cerebrovascular Accident, Acute Myocardial Infarction, Spice, Seizures, JWH210, AM2233

\section{Introduction}

Many ancient cultures throughout the world had used cannabis-derived products e.g. Chinese, Indian, and Tibetan [1]. The seeds and fruits of Cannabis sativa were used to treat gastrointestinal disturbances, seizures, pain of childbirth, snake bites and many more [2]. The psychoactive properties of cannabis were also realized long ago and therefore it was used in religious ceremonies, such as these conducted by Tantric, Buddhists, Hindus, and ancient Shamans [2]. In addition to medicinal and religious uses, cannabis has been widely employed as a recreational drug for centuries [1]. Several clinically available products of either $\Delta^{9}-$ tetrahydrocannabinol $\left(\Delta^{9}-\mathrm{THC}\right)$, the principle psychoactive component of marijuana, or structurally related derivatives are available for safe and efficacious treatment for several 
diseases when administered appropriately and under proper medical supervision [3]. Unfortunately $\Delta^{9}-$ THC based drugs produce both therapeutic and undesirable psychotropic actions by activating cannabinoid receptors (CB1Rs) in the Central Nervous System (CNS).

A number of classical cannabinoids, $\Delta^{9}-$ THC analogs, have been synthesized since 1960's [4]. "Spice" is a rapidly emerging drug of abuse that gained popularity among adolescence and young adults since first introduced to the market in 2004. Spice is an umbrella term for a variety of synthetic marijuana products [5]. Although spice products are structurally distinct from $\Delta^{9}-$ THC, they contain aminoalkylindole a non classical cannabinoids that also bind and activate CB1Rs, in fact many of cannabnoids found in samples of spice products have an affinity for CB1Rs that is 4-5 times greater than $\Delta^{9}-$ THC and have demonstrated greater potency compared with $\Delta^{9}-$ THC [5]. Although spice was declared as "incense blend which releases a rich aroma and not for human consumption", when smoked as "bio- drug", has been reported by some users to have effects similar to those of cannabis [6]. Spice and other herbal products are often referred to as "legal highs" or "legal marijuana", in reference to their legal status and purported natural herbal make-up [5]. Their is lack of clinical information related to the pharmacology of the compounds within spice in man and this lack of information presents great concern to clinicians and public health officials. In addition to the active ingredients, the plant material used for manufacturing spice as well as varying product mixtures may lead to unexpected toxic outcome [7]. Adverse clinical effects reported with use of spice products are; anxiety, confusion, paranoia, tachycardia, hypertension, hypokalemia, hyperglycemia, nausea, vomiting, conjunctivitis, mydriasis, fever, and irritation [5]. More serious side effects such as seizure and to a lesser degree ICVA[8], rare cases of MI and transient ischemic attacks have been reported in previously healthy young men in their twenties who used spice [ 7,9,10,11-18] Table 1 .

Table 1. Cases of MI, ICVA and seizures reported in literatures in previously healthy young people who used synthetic marijuana.

\begin{tabular}{|c|c|c|c|c|c|c|c|c|}
\hline Case & Age & Gender & Race & Substance & MI & ICVA & Seizure & Published \\
\hline \multirow{2}{*}{ Freeman MJ, et al. } & A. $26 \mathrm{y} / \mathrm{o}$ & Male & Unknown & JWH-018 & \multirow[b]{2}{*}{ No } & \multirow[b]{2}{*}{ Yes } & \multirow[b]{2}{*}{ No } & \multirow[b]{2}{*}{$\mathrm{Dec} / 13$} \\
\hline & B. $19 \mathrm{y} / \mathrm{o}$ & Female & Unknown & + natural marijuana & & & & \\
\hline \multirow{2}{*}{$\begin{array}{l}\text { Bernson-Leung ME, } \\
\text { et al. }\end{array}$} & & & & & \multirow{2}{*}{ No } & \multirow{2}{*}{ Yes } & \multirow{2}{*}{ No } & \multirow{2}{*}{ Dec/13 } \\
\hline & B. 26 y/o & Female & Unknown & + salicylates & & & & \\
\hline \multirow{2}{*}{ Harris CR, et al. } & A. 19 y/o & Female & Unknown & A.Bayou Blaster & \multirow{2}{*}{ No } & \multirow{2}{*}{ No } & \multirow{2}{*}{ Yes } & \multirow{2}{*}{$\mathrm{Feb} / 13$} \\
\hline & & Male & unknown & B. $\mathrm{K} 2$ + natural marijuana & & & & \\
\hline Tofighi B, et al. & $48 \mathrm{y} / \mathrm{o}$ & Male & unknown & JWH-018 + K2 & No & No & Yes & Sep/12 \\
\hline Young AC, et al. & $17 \mathrm{y} / \mathrm{o}$ & Male & Unknown & $\begin{array}{l}\text { K9 (JWH-018 } \\
\text { JWH-073)+ Alcohol }\end{array}$ & $\begin{array}{l}\text { Chest pain with } \\
\text {-ve troponin }\end{array}$ & No & No & $\mathrm{Sep} / 12$ \\
\hline Schneir AB, et al. & $19 \mathrm{y} / \mathrm{o}$ & Male & unknown & $\begin{array}{l}\text { JWH-018, JWH-081, JWH-250, } \\
\text { AM-2201 }\end{array}$ & No & No & Yes & Mar/12 \\
\hline \multirow{3}{*}{ Mir A, et al. } & A. $16 \mathrm{y} / \mathrm{o}$ & Male & Unknown & $\mathrm{K} 2(\delta-9-\mathrm{THC})$ & Yes & No & No & \multirow{3}{*}{ Dec/11 } \\
\hline & B.16 y/o & Male & Unknown & $\mathrm{K} 2$ & Yes & No & No & \\
\hline & C.16 y/o & Male & unknown & THC & Yes & No & No & \\
\hline De Havenon, et al. & $\begin{array}{l}\text { A. } 24 \mathrm{y} / \mathrm{o} \\
\text { B. } 36 \mathrm{y} / \mathrm{o}\end{array}$ & $\begin{array}{l}\text { Male } \\
\text { Female }\end{array}$ & $\begin{array}{l}\text { Unknown } \\
\text { Unknown }\end{array}$ & $\begin{array}{l}\text { A. Funky monkey spice } \\
\text { B. Black mamba spice }\end{array}$ & No & No & Yes & Oct/11 \\
\hline
\end{tabular}

Based on extensive review of the literature we here present a case that appears to be the first case report where a single spice abuser develops ICVA, uncontrolled seizures and acute MI with negative workup towards the etiology other than spice abuse.

\section{Case Description}

A 23 years old African American male, who initially presented to the hospital two years ago with sudden expressive aphasia and generalized headache. His symptoms started 2 hours after he inhaled spice for the first time. CT scan of the head showed hypoattenuation of the left frontoparietal region (Figure 1). MRI confirmed the presence of middle cerebral artery infarct and the diagnosis of left parietal lobe ischemic stroke was established. Upon further questioning, he reported smoking spice and denied other recreational drug use, the spice package that has been provided by this patient indicates that it contains "A mixture of dried flower petals with spice, it may contain wild lettuce, red clover, basil, spearmint, peppermint, chamomile flowers, hops, strawberry leaves and patchouli leaves, and it does not contain JWH 18, JWH200, JWH73, JWH250, JWH 19, JWH 398, HU 210, HU211, CP47/497,"C8" 47/497 and that it was "not for human consumption" (Figure 1). Toxicology analysis was done and it showed the presence of JWH210 and AM2233 both of these are Synthetic marijuana. 


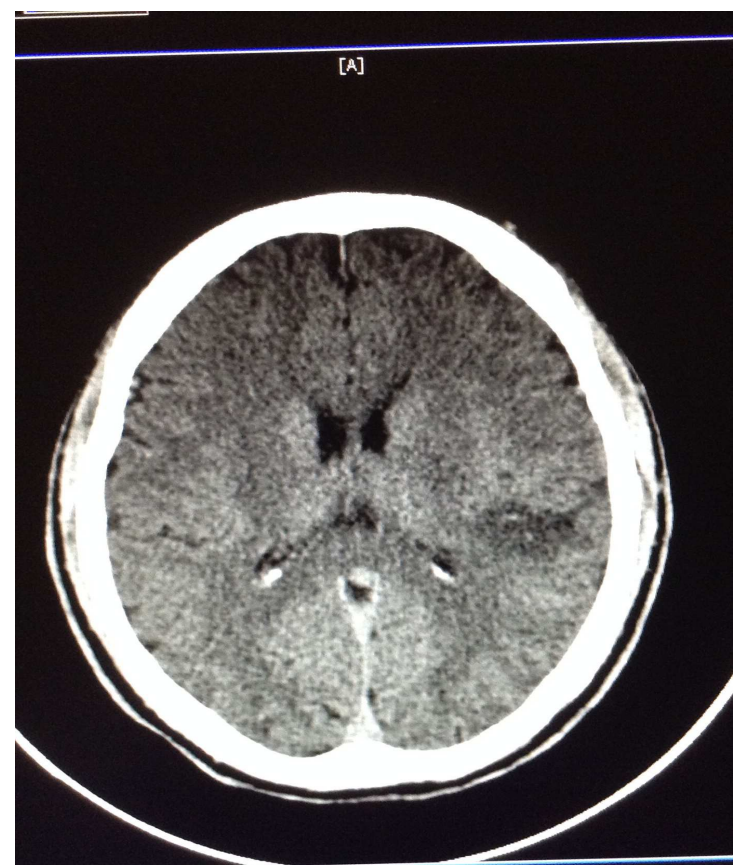

Figure 1. CT head taken to the patient in his first admission showing left parietal lobe ischemic stroke

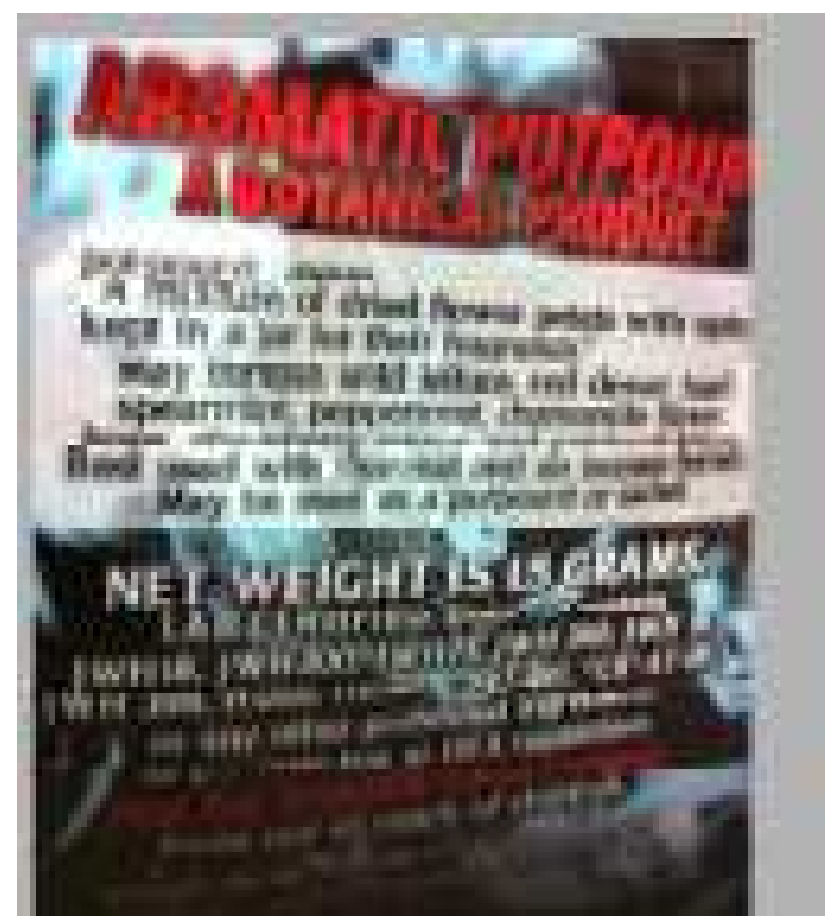

Figure 2. back of the packet of the synthetic marijuana provided by the patient in his first admission.

The patient was started on Aspirin and Statins and discharged to follow up with speech therapist and was counseled extensively against the use of spice but he did not comply.

After this incident and in the span of two years he was admitted to the hospital three times with uncontrolled seizures. He had no past history of convulsions nor was he on any medication. There was a chronological correlation between his seizures and spice abuse in all of these admissions.

Last time he was admitted to the hospital for seizures, while admitted he developed pressure like chest pain subsequently he was found to have elevated Troponin I with EKG changes. A diagnosis of Acute MI was made. Given the patient's age and the absence of risk factors a thorough work up was conducted including a comprehensive drug screen that tests for more than 30 compounds and their metabolites, the urine test was only positive for spice.

\section{Discussion}

The use of spice is widespread among teenagers and young adults in the US. In 2012, a report estimated that $11 \%$ of high school seniors have experienced this substance in the past year [19]. The currently used rapid urine immunoassay does not detect spice and abusers can pass undetected on regular basis, this may be a large part of the products appeal.

Little data are available about the pharmacokinetics and pharmacodynamics of the synthetic cannabinoids, they have primarily studied in vitro and their clinical effects in humans are limited [20]. The cardiac risks such as MI may be attributed to the relatively large amount of carbon monoxide absorbed when smoking spice. The deep inhalation and the long inspiratory times adopted by spice smokers may increase carboxyhemoglobin concentrations that may cause this atheromatous disease [21], or may be that the toxicity of the synthetic cannabinoids, the plant matter, or the unknown adulterants used in the production of spice causes side effects which are not typically encountered following marijuana use [22].

Another possible cause of cardiac risks is that some of the synthetic cannabinoids may cause tachycardia and vasospasm due to their nearly 4 fold increased affinity to CB1R and 10 fold increased affinity to CB2R (cannabinoid receptor 2) present mainly on immune system $[6,23]$.

The mechanism linking synthetic cannabinoids to seizures is currently unclear. It may be due to the synthetic cannabinoids themselves or due to another substance present within the synthetic cannabinoid product. Marijuana and its active ingredients possess anticonvulsant effects in animal model and humans and it has been used as treatment for epilepsy before the development of anti-epilepsy drugs [24, 25]. When spice is extensively tested, spice products have been found to have multiple synthetic cannabinoids, but not co-existant phytocannabinoids $\left(\Delta^{9}-\right.$ THC, cannabinol, cannabidiol and $\Delta^{9}$ - tetrahydrocannabivarin ), cannabidiol and its derivatives have been shown to be consistently anticonvulsant in animal models [26-28], and in limited human trials $[29,30] . \Delta^{9}-$ tetrahydrocannabivarin was also recently demonstrated to exert anticonvulsant properties [31]. The absence of phytocannabinoids in synthetic cannabinoid products may result in an increased risk of seizures in users [32]. Although we did not specifically exclude the presence of the anticonvulsant phytocannabinoids in the product used by our patient, however the confirmed absence of $\Delta^{9}-$ THC would make their presence seem extremely unlikely. 
It has also been found that cannabinoids decrease both glutamate and $\gamma$-aminobutyric acid (GABA) synaptic transmission in the brain [33]. Decreasing the excitatory neurotransmitter glutamate decreases seizure susceptibility, while decreasing the inhibitory neurotransmitter GABA increases seizure susceptibility. When wild-type mice administered a synthetic cannabinoids, GABA synaptic transmission decreased, while CB1R knochout mice showed no decrease in GABA synaptic transmission. Besides, there was a decrease in glutamate synaptic transmission in both the wild-type and the knockout mice. This suggests that a novel cannabinoids-sensitive receptor is responsible for the inhibition of glutaminiergic neurotransmission [22]. The synthetic cannabinoids are full agonists of the CB1R and their full agonism of the GABA CB1R may lead to a more potent epileptogenic decrease in GABA synaptic transmission without the concurrent effects of the novel cannabinoid-sensitive glutamate receptors [34, 35].

The diagnosis of spice encephalopathy with ICVA or seizure can be challenging because it may mimic some aspects of serotonin syndrome and neuroleptic malignant syndrome and does not have a simple laboratory test to make the diagnosis compared to other drug screens. Therefore, this disorder requires a high index of suspicion in making the clinical diagnosis and spice use should be considered in patients who mimic the triad of serotonin-like syndrome, like autonomic (tachycardia, hypertension), neuromuscular (asterixis or myoclonus), and CNS (seizures, encephalopathy) findings. In a previous report of two siblings who developed ischemic stroke after smoking spice, authors suggested that the ischemic stroke is of cardioembolic etiology, because smoking spice has been associated in the medical literature with MI [36].

Chemical analysis of the spice sample provided by our patient in his first admission indicates the presence of two synthetic cannabinoids; JWH 210 and AM2233. JWH 210 is a potent cannabimimetic alkylindole that has been identified in extracts from herbal blends. JWH $210 \mathrm{~N}$-(5-hydroxypentyl) metabolite is an expected metabolite of JWH 210, and is detectable in the serum and urine. Comparison of the synthetic cannabinoids confirmed in biological samples from seizure patients (with no prior history of seizures) with the presence of synthetic cannabinoids in the product, suggest that JWH-210 and other synthetic marijuana like JWH-018, JWH-122, AM-2201 may have an involvement in lowering seizure thresholds [37].

Adverse cardiovascular effects associated with JWH-210 use are largely limited to changes in resting heart rate and changes in blood pressure [38], the lowest serum concentration to induce changes to the blood pressure was $0.2 \mathrm{ng} / \mathrm{mL}$ of JWH-210, and the highest serum concentration was $190 \mathrm{ng} / \mathrm{mL}$ of JWH-210.

AM-2233 (1-[(N-methylpiperidin-2-yl) methyl]-3-2iodobenzoyl) indole) is a drug that acts as a highly potent full agonist to CB1R. AM-2233 was developed for use as a selective radioligand for mapping the distribution of the $\mathrm{CB} 1 \mathrm{R}$ in the brain; recently, however, AM2233 has received attention as a cannabimimetic acquired for recreational use as a "legal high" replacement for restricted substances [39]. The European Monitoring Center for Drugs and Drug Addiction (EMCDDA) in their Early Warning System Report 2011 reported seizure in Finland after AM-2233 abuse [40].

The patient presented in this paper has been admitted to the hospital several times after having serious side effects due to spice abuse during the period of two years, whether the development of more severe side effects is related to chronic use or due to different substances that are present in different batches of spice needs further investigation.

\section{Conclusion}

Given the patient negative history for thromboembolization, vasculitis, and hypercoagulable state, the multiple admissions of this patient after smoking spice, and the positive drug screen test for spice, we hypothesize that synthetic marijuana or the herbs mixed with it might cause the ICVA, MI and seizures in his last admission.

In general there is lack of information about problems related to chronic spice use and this paper gives an insight that devastating and more severe side effects may take place after chronic use, or may be the severe side effects that this patient encounter in the last admission related to higher dose of the toxic substance or different substance within the spice batch that he used.

\section{Limitations}

Laboratory analysis for synthetic cannabnoids and interpretation of results is complicated, most laboratories cannot test for these agents because the development of standards is slow, and of the laboratories that offer testing, they assess for less than 20 of the available synthetic cannabnoids $[41,42]$. Another limitation in our case report; we were unable to obtain spice sample from patient in every admission, this makes it difficult to know the active ingredients in spice sample that led to the signs and symptoms the patient present with in each admission.

\section{Recommendation}

This paper aims toward raising awareness of the medical society about the danger and the life threatening consequences after synthetic marijuana abuse. Besides youngsters needs to be informed about the real dangers of spice use, and awareness campaigns should be started in high schools and colleges. Finally the legislative authorities should be urged to legally ban those compounds all together (not one by one!)

\section{Acknowledgment}

Authors would like to thank toxicology laboratory at Beaumont Hospital for analyzing the spice sample. 


\section{Declaration of Conflicting Interests}

The author(s) declared no potential conflicts of interest with respect to the research, authorship, and or publication of this article.

\section{Funding}

The author(s) received no financial support for the research, authorship, and or publication of this article.

\section{References}

[1] Zuardi AW (2006) History of Cannabis as a medicine: a review. Rev Bras Psiquiatr 28, 153-157.

[2] Touw M (1981) The religious and medicinal uses of Cannabis in China, India and Tibet. J Psychoactive Drugs 13, 23-34.

[3] Turcotte D, Le Dorze JA, Esfahani F, Frost E, Gomori A, and Namaka M (2010) Examining the roles of cannabinoids in pain and other therapeutic indications: a review. Expert Opin Investig Drugs 11, 17-31.

[4] Uchiyama, N, Kikura-Hanjiri R, Kawahara N, Haishima Y, and Goda Y (2009) Identification of a cannabinoid analog as a new type of designer drug in a herbal product. Chemical and Pharmaceutical Bulletin 57 (4), 439-441.

[5] Seely, KA, Prather, PL, James, LP, Moran, JH (2011) Marijuana-based drugs: innovative therapeutics or designer drugs of abuse? Mol Interv 11(1), 36-51

[6] Auwarter V, Dresen S, Weinmann W, Muller M, Putz M, and Ferreires N (2009) "Spice" and other herbal blend: harmless incense or cannabinoid designer drugs? J Mass Spectrom 44, 832-837

[7] EMCDDA (2009) Understanding the "Spice" phenomenon. European Monitoring Center for Drugs and Drug Addiction EMCDDA 2009 Thematic paper Ed., Office for Official Publications of the European Communities

[8] Price MR, Baillie GL, Thomas A, Stevenson LA, Easson M, Goodwin R, McLean A, Mcintosh L, Goodwin G, Walker G (2005) Allosteric modulation of the cannainoid CB1 receptor. Mol Pharmacol 68, 1484-1495

[9] Di Marzo V, Petrosino S (2007) Endocannabinoids and the regulation of their levels in health and disease. Curr Opin Lipidol 18, 129-140

[10] Ashton CH (1999) adverse effects of cannabis and cannabinoids. British J of Anaesthesia 83(4), 637-649

[11] Freeman MJ, Rose DZ, Myers MA, Gooch CL, Bozeman AC, Scott Burgin W (2013) Ischemic stroke after use of the synthetic marijuana "spice" Neurology 81 (24), 2090-2093.

[12] Bernson-Leung ME, Leung LY, Kumar S (2013) Synthetic cannabis and acute ischemic stroke. J Stroke Cerebrovasc Dis 23(5), 1239-1241

[13] Harris CR, Brown A 2013 Synthetic cannabinoids intoxication: a case series and review. J Emerg Med 44, 360-366.
[14] Tofighi B, Lee JD (2012) Internet highs-seizures after consumption of synthetic cannabinoids purchased online. $J$ Addict Med 6, 240-241

[15] Young AC; Schwarz E; Medina G; Obafemi A; Feng SY; Kane $C$; Kleinschmidt $K$ (2012) Cardiotoxicity associated with the synthetic cannabinoid, K9, with laboratory confirmation. Am J Emerg Med 30(7), 1320-1327

[16] Schneider AB,Culen J, Ly BT (2011) "spice" girls: synthetic cannabinoids intoxication. J Emerg Med 40, 296-299

[17] Mir A, Obafemi A, Young A, Kane C (2011) Myocardial infarction associated with the use of synthetic cannabinoids k2 Pediatrics 128, 1622-1627

[18] De Havenon A, Chin B, Thomas KC, Afra P (2011) The Secret "Spice": An Undetectable Toxic Cause of Seizure. Neurohospitalist 1(4), 182-186.

[19] Monitoring the Future Survey (2012) 2. Drug Abuse Warning Network, 2012

[20] Varadakou I, Pistos C, Spilliopoulou C (2010) Spice drugs as a new trend: mode of action, identification and legislations. Toxicol Lett 197(3), 157-162)

[21] Mortati K, Dworetzky B, Devinsky O (2007) Marijuana: an effective antiepileptic treatment in partial epilepsy? A case report and review of the literature. Rev. Neurol Dis 4(2), 103106

[22] Hajos N, Ledent C, Freund TF (2001) Novel Cannabinoidsensitive receptor mediates inhibition of glutamate synaptic transmission in the Hippocampus. Neuroscience 106(1), 1- 4

[23] Wintermeyer A, MollerI, Thevis M, Jubner M, Beike J, Rothschild MA, Bender K (2010) In vitro phase I metabolism of the synthetic cannabinomimetic JWH-018. Anal Bioanal Chem 398(5), 2141-2153

[24] Grinspoon L, Bakalar J (1997) Marihuana: The forbidden medicine. New Haven, CT: Yale University press, 66-81

[25] Lutz B (2004) On demand activation of the endocannabinoid system in the control of neuronal excitability and epileptiform seizures. Biochem Pharmacol 68(9), 1691-1698.

[26] Gordon E, Devinsky O. (2001) Alcohol and marijuana: effects on epilepsy and use by patients with epilepsy. Epilepsia. 42:1266-1272.

[27] Karler R, Turkanis SA (1981) The cannabinoids as potential antiepileptics. J Clin Pharmacol 21, :437S-448S.

[28] Consroe P, Martin A, Singh V (1981) Antiepileptic potential of cannabidiol analogs. J Clin Pharmacol 21, 428S-436S.

[29] Cunha JM, Carlini EA, Pereira AE, Ramos OL, Pimentel C, Gagliardi R, Sanvito WL, Lander N, Mechoulam R (1980) Chronic administration of cannabidiol to healthy volunteers and epileptic patients. Pharmacology 21, 175-185.

[30] Carlini EA, Cunha JM (1981) Hypnotic and antiepileptic effects of cannabidiol. J Clin Pharmacol 21, 417S-427S.

[31] Turcotte D, Le Dorze JA, Esfahani F, Frost E, Gomori A, and Namaka M (2010) Examining the roles of cannabinoids in pain and other therapeutic indications: a review. Expert Opin Investig Drugs 11, 17-31 
[32] Uchiyama, N, Kikura-Hanjiri R, Kawahara N, Haishima Y, and Goda Y (2009) Identification of a cannabinoid analog as a new type of designer drug in a herbal product. Chemical and Pharmaceutical Bulletin 57 (4), 439-441

[33] Nutt D. Consideration of the major cannabinoid agonist advisory council on the misuse of drugs. July 16, 2009.)

[34] De Petrocellis L, Di Marzo V (2009) An introduction into the endocanabinoid system: from the early to the latest concepts. Best Pract Res Clin Endocrinol Metab 23(1), 1-15

[35] Wehrman J. Fake marijuana spurs more than 2,000 calls to U.S. Poision centers this year alone. American Association of Poison Control Centers. November 22,2010

[36] Freeman WD, Louth IK, Gooch CL, Freeman MJ, Rose DZ, Burgin WS (2014) Ischemic stroke after use of the synthetic marijuanan "spice" . Neurology 83 (8), 773- 777

[37] Makriyannis A, Deng H: Cannabimimetic Indole Derivatives; US patent 7241799; http://www.patentlens.net/patentlens/patents.html?patnums=U S_7241799\&language $=\&($ accessed November 15,2013$)$
[38] Hermanns-Clausen M, Kneisel S, Szabo B, Auwärter V(2012) Acute toxicity due to the confirmed consumption of synthetic cannabinoids: Clinical and laboratory findings. Addiction 108,534

[39] Deng H, Gifford AN, Zvonok AM, Cui G, Li X, Fan P, Deschamps JR, Flippen-Anderson JL, Gatley SJ, Makriyannis A (2005) protein cannabinergic indole analogues as radioiodinatable brain imaging agents for the CB1 cannabinoid receptor. J Med Chem 48, 6386-6392

[40] The EMCDDA (2011) Synthetic Cannabinoids and "spicee

[41] Moller I, Wintermeyer A, Bender K (2010) screening for the synthetic cannabinoids JWH-018 and its major metabolites in human doping controls. Drug Test Anal

[42] Sobolevesky T, Prasolov I, Rodchenkov G (2010) Detection of JWH-018 metabolites in smoking mixture post-administration urine. Forensic Sci Int 200(1-3), 141-147 